\title{
Consequences of Reducing the Cost of PV Modules on a PV Wind Diesel Hybrid System with Limited Sizing Components
}

\author{
Jones S. Silva, Alice R. Cardoso, and Alexandre Beluco \\ Instituto de Pesquisas Hidráulicas, Universidade Federal do Rio Grande do Sul, 90570-901 Porto Alegre, RS, Brazil \\ Correspondence should be addressed to Alexandre Beluco, albeluco@iph.ufrgs.br
}

Received 31 October 2011; Accepted 26 December 2011

Academic Editor: Jincai Zhao

Copyright (C 2012 Jones S. Silva et al. This is an open access article distributed under the Creative Commons Attribution License, which permits unrestricted use, distribution, and reproduction in any medium, provided the original work is properly cited.

The use of renewable resources for power supply in family homes has passed the stage of utopia to became a reality, with limits set by technical and economic parameters. This paper presents the results of a project originated from the initiative of a middle-class family to achieve energy independence at home. The starting point was the concept of home with "zero energy" in which the total energy available is equal to the energy consumed. The solution devised to meet the energy demand of the residence in question is a PV wind diesel hybrid system connected to the grid, with the possibility of energy storage in batteries and in the form of heating water and the environment of the house. As a restriction, the family requested that the system would represent little impact to the lifestyle and landscape. This paper aims to assess the consequences of reductions in the cost of the PV modules on the optimization space, as conceived by the software Homer. The results show that for this system, a 50\% reduction in the cost of PV modules allows all viable solutions including PV modules.

\section{Introduction}

Renewable energy is more suitable for decentralized use, with the energy converters located close to consumers and providing supplies at concentrations far lower than those obtainable with nonrenewable resources. Among the renewable resources with technical and economic viability to meet the demands of households are mainly solar and wind power.

The photovoltaic modules can be used to meet the demands of small houses in places where sunlight reaches a reasonable annual amount of energy available. However, the costs of PV modules are still quite high and derail its acquisition in an amount sufficient to supply all annual energy demanded by a typical middle class home. But it is possible to design systems that have the support of a diesel generator or are connected to the system and are able to meet this energy demand.

Photovoltaic systems provide a power supply that has its own characteristics and availability of energy concentration. A greater penetration of photovoltaic components in hybrid systems necessarily require a reduction in their costs. The increase in world production of photovoltaic modules and a greater number of incentive programs for installation of photovoltaic modules, among some other factors, could enable reductions in the costs of photovoltaic modules.

This paper presents the results of a research project originated from the initiative of a middle-class family to achieve energy independence at home. The starting point was the concept of home with "zero energy" [1] in which all the energy of the house is from renewable sources and the total energy available is equal to the energy consumed. A preliminary analysis revealed that the renewable resources available are solar and wind energy. The high cost of PV modules makes a renewable-only system infeasible.

The solution devised to meet the energy demand of the residence in question is a PV wind diesel hybrid system connected to the grid, with the possibility of energy storage in batteries and in the form of heating water and the environment of the house. The purchase of energy needed in periods of low-solar availability and sale of surplus energy to the energy system to reduce dependence on diesel fuel.

As an important restriction, the family that lives in the house for which the study was conducted requested that each component of the system was included with few 


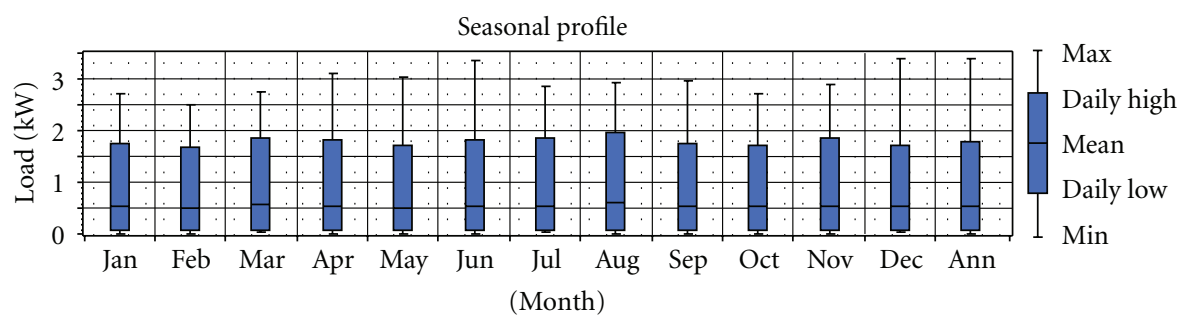

(a)

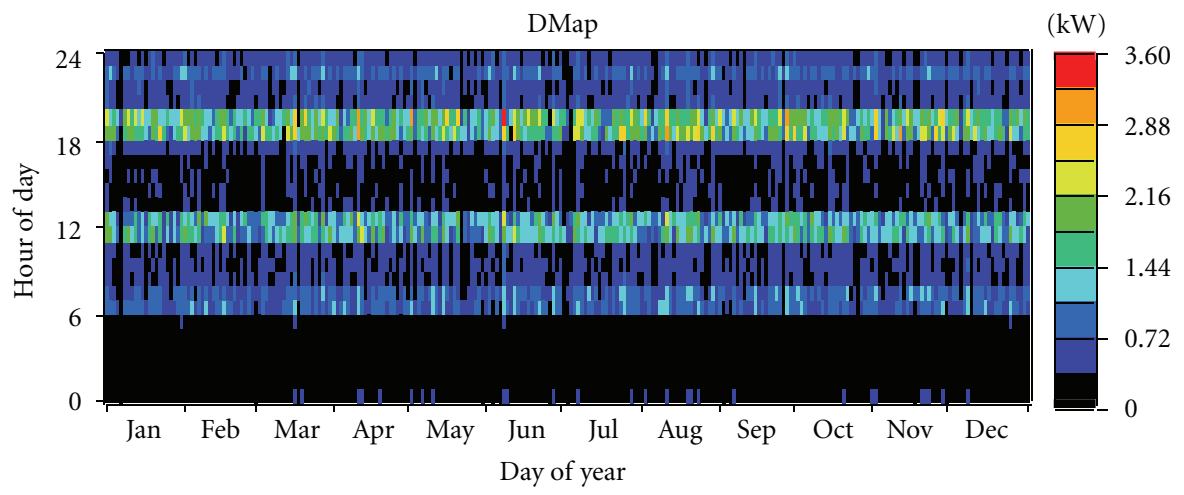

(b)

FIGURE 1: Average daily demand profile of the house considered in the study.

components to avoid an excessive impact on their lifestyle or the landscape and reduce costs with works by adapting the home. For example, they requested that the battery bank or that the wind turbines on the roof do not take on excessive dimensions.

The sequence of the project aimed to determine the costs that must be met by the photovoltaic modules to enable a substantial increase in its penetration in the system devised for this purpose. Specifically, this paper aims to relate a possible reduction of costs of the modules with the increase of possible solutions to the system design that includes modules.

\section{The House That Was the Reference for This Study}

The house considered in this study is a middle-class residence of $160 \mathrm{~m}^{2}$, with two bedrooms, living room, kitchen, and two bathrooms, located in the city of Porto Alegre, capital of Rio Grande do Sul, southern Brazil. The house is occupied by a family with five members (father, mother, and three small children) and is equipped with typical middle-class household appliances and heating system.

Electrical demand is shown in Figure 1 and the demand for water heating is shown in Figure 2. The total electric power installed in the house is $9.00 \mathrm{~kW}$ with a peak power of $2.61 \mathrm{~kW}$ and a load factor of 0.160 , resulting from basic appliances like refrigerator, television set, microwave oven, washing machine, some lamps with high efficiency and, eventually, a blender, hair dryer, and electric shaver. The average consumption is $0.417 \mathrm{~kW}$ and $10 \mathrm{kWh} / \mathrm{d}$. The profile of demand for electricity was generated synthetically from the average consumer.

The Figure 1 shows two graphs. At first, the average electrical demand for each month, the deviations around these averages and maximum and minimum values are shown. The second graph consists of a diagram that summarizes the distribution of electrical demand for each hour of the day over all days of the year, according to the legend on the right. In this case, consumption peaks are observed at around noon and late afternoon, between 18 hours and 20 hours, and periods of low consumption are observed before six in the morning and peaks between noon and late in the afternoon.

The total power for water heating is $5.80 \mathrm{~kW}$ with a load factor of 0.108 , corresponding to the demand for water heating and space heating, with an average consumption of $0.625 \mathrm{~kW}$ and $15 \mathrm{kWh} / \mathrm{d}$. The thermal loads associated with the boiler have an efficiency of $60 \%$ and are filled with diesel fuel. The demand profile was generated synthetically from the monthly average values attributed to consumption forecasts for warming over the several months of the year. This structure for heating water is usually turned off during the summer months.

The Figure 2 also shows two graphs. At first, the average thermal demand for each month, the deviations around these averages and maximum and minimum values are shown. In this case, there is no consumption in summer months and an annual peak consumption in the month of August is evident. In the second graph, the lack of consumption in summer months is evident. Similarly, consumption peaks appear between July and September. 


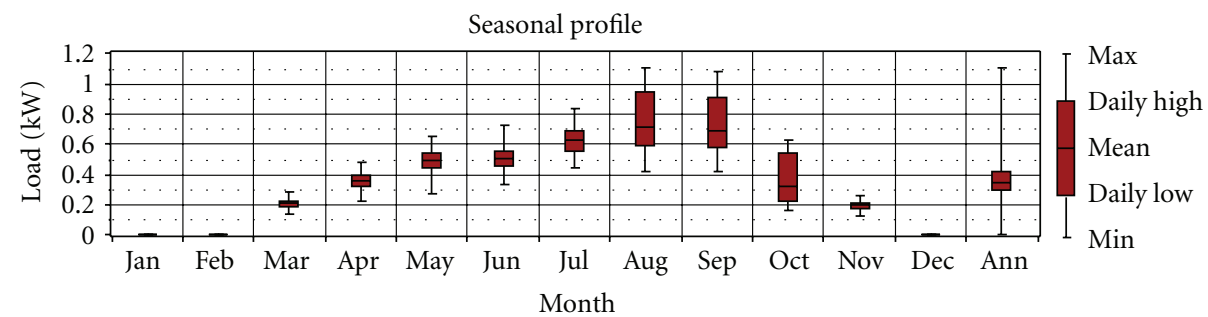

(a)

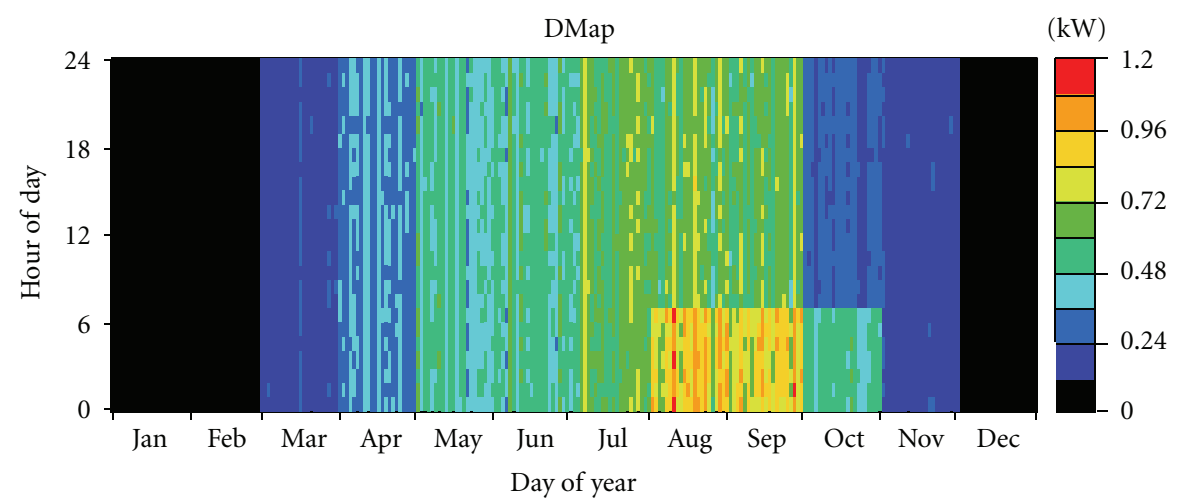

(b)

FIgURE 2: Profile of average daily demand for water heating and space heating.

\section{Components of the Energy System}

The power supply to the house in this study can be obtained from photovoltaic modules, small wind turbines, and a generator-based diesel. The connection to the energy system should not be closed, but should be considered as an alternative when there is less availability of solar energy, when the cost of fossil fuel and when the emissions associated with fossil fuel consumption have exceeded preestablished limits.

The diesel system consists of a diesel generator based on fossil fuel to supply power to the house considered in this study, always in support of electrification with renewable resources. The average cost of diesel is about USD \$ 1.50 per liter. The acquisition cost for equipment with $1 \mathrm{~kW}$ is USD\$ 500 and the replacement cost is US\$ 400, with operating and maintenance costs estimated at USD $\$ 0.05$ per hour and lifetime estimated at 15,000 hours.

The diesel oil consumption is associated with emission of $6.5 \mathrm{~g}$ of carbon monoxide per liter of diesel oil, $0.72 \mathrm{~g}$ of hydrocarbons consumed per liter, $0.49 \mathrm{~g}$ of particulate matter per liter, $2.2 \%$ sulfur converted into particulate matter, and $58 \mathrm{~g}$ of nitrogen oxides per liter. Emission limits may be established in order to prevent significant increases in the use of these systems.

The software HOMER [2] allowed the acquisition of data from solar availability in Porto Alegre, where the house is located. Figure 3 shows the solar radiation incident on a horizontal plane. The acquisition cost for PV modules is about USD $\$ 8,000 / \mathrm{kW}$, with replacement cost of USD\$ $7,000 / \mathrm{kW}$ and maintenance cost of US\$ 100 per year and lifetime estimated at 12.5 years.
The Figure 3 also shows two graphs. At first, the average incident solar radiation on a horizontal plane for each month, the deviations around these averages and maximum and minimum values are shown. The maximum insolation occurs in the month of January, while the minimum occurs in June. In the second graph, it is evident the variation of sunlight available throughout the hours of the day, with the lowest values available in the first and the last hour of the day, and the available peak near midday. Also evident is the change in hours of the day throughout the year.

The wind system consists of small turbines used to recharge batteries [3], manufactured by southwest windpower, with $0.55 \mathrm{~kW}$. The equipment was installed in a tower on the roof, to reduce impacts to the landscape. The series of wind data is synthetic, made from parameters for the region, shown in Figure 4 . The acquisition cost is USD\$ 2,000 , with replacement cost of USD $\$ 1,800$ and operating and maintenance cost of USD $\$ 100$ per year and lifetime estimated at 12.5 years.

The Figure 4 also shows two graphs. At first, the average wind speed for each month, the deviations around these averages and maximum and minimum values are shown. This graph shows the typical variability of the wind. The second graph, with strong variation in color, enhances the variability of the wind.

The alternatives considered for the power supply still contain inverters, rectifiers, batteries, and specific electric charges, allowing the flow of energy between the DC bus and $\mathrm{AC}$ power and energy storage in chemical and thermal forms.

In this paper, converters, which include a single component in the functions of inverters and rectifiers, were used. 


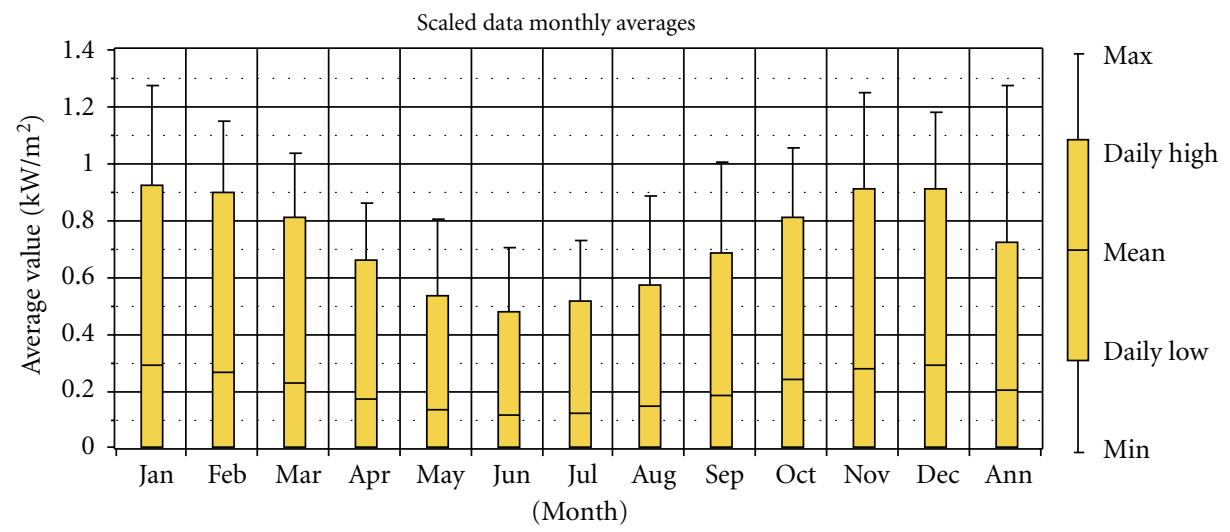

(a)

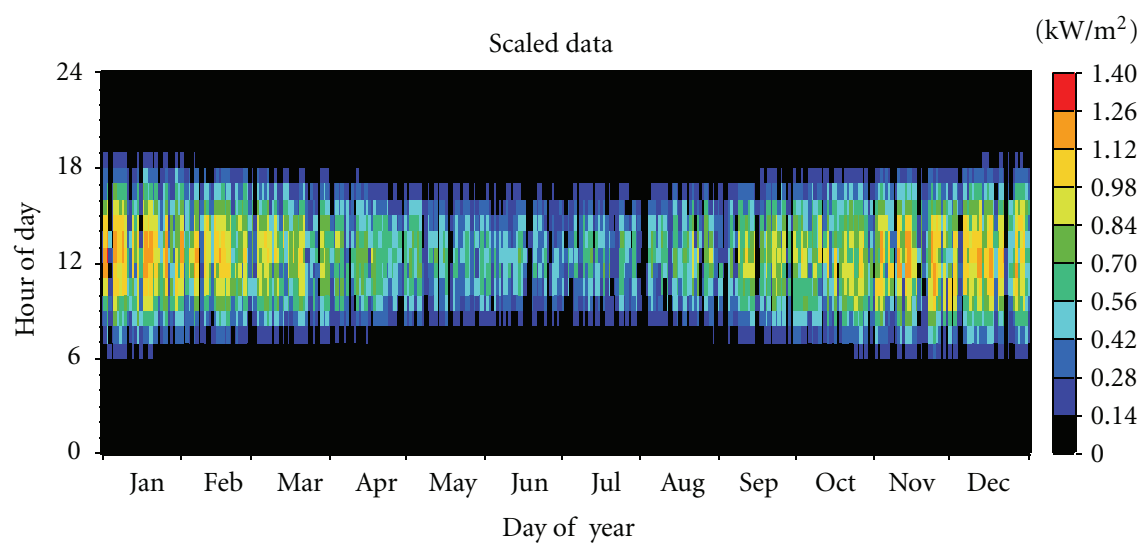

(b)

FIGURE 3: Incident solar radiation on a horizontal plane, obtained with software Homer.

The device can operate as rectifier and inverter with $100 \%$ of total capacity, with $85 \%$ performance. The lifetime is estimated at 12.5 years.

Batteries 6FM55D model was adopted in the simulation [4]. This model is part of the database software and has features very similar to the batteries available in the local market. Automotive batteries were adopted by their availability in the market and its low cost. The model operates with $12 \mathrm{~V}$, with nominal capacity of $55 \mathrm{Ah}$, equivalent to $0.66 \mathrm{kWh}$, with lifetime throughput of $256 \mathrm{kWh}$. The acquisition cost is USD\$100, with replacement cost of USD\$ 90.

The connection to the grid is considered, with the cost of USD\$ 0.28 per $\mathrm{kWh}$, without cost to hiring demand, as is usual for residential consumers. There is no charging differential tariffs for consumption at peak time for residential consumers.

\section{Simulations with Homer}

The software Homer [2], the micropower optimization model, was developed by National Renewable Energy Laboratory (NREL) and is available for universal access in its version 2.68 beta. HOMER simulates a system for power generation over the time period considered in the project at intervals of 60 minutes, presenting the results for a period of one year $[5,6]$.

The simulations were performed for an operation period of 25 years, with $12 \%$ annual interest and 6\% internal rate of return. It was also established that the different generators could operate simultaneously and in parallel.

Simulations use a diesel hybrid photovoltaic and independent use of the same hybrid with the ability to connect to the energy system was made. With the first, the assessment of whether the house be kept autonomous, independent of external power supply is required. With the second system, the evaluation of their performance in interconnected operation is possible.

The hybrid system designed for independent supply of energy is represented schematically in Figure 5. It is a diesel hybrid photovoltaic system that allows the accumulation of energy in a battery bank and in the form of heat by heating water and the home environment.

The system includes an AC bus and the other in DC, with the first receiving supplies of diesel generator and the second photovoltaic and wind generators. The electrical load is connected to the AC bus and battery bank to the DC bus, with the energy flow in both directions between the two buses made possible by the converter device. 


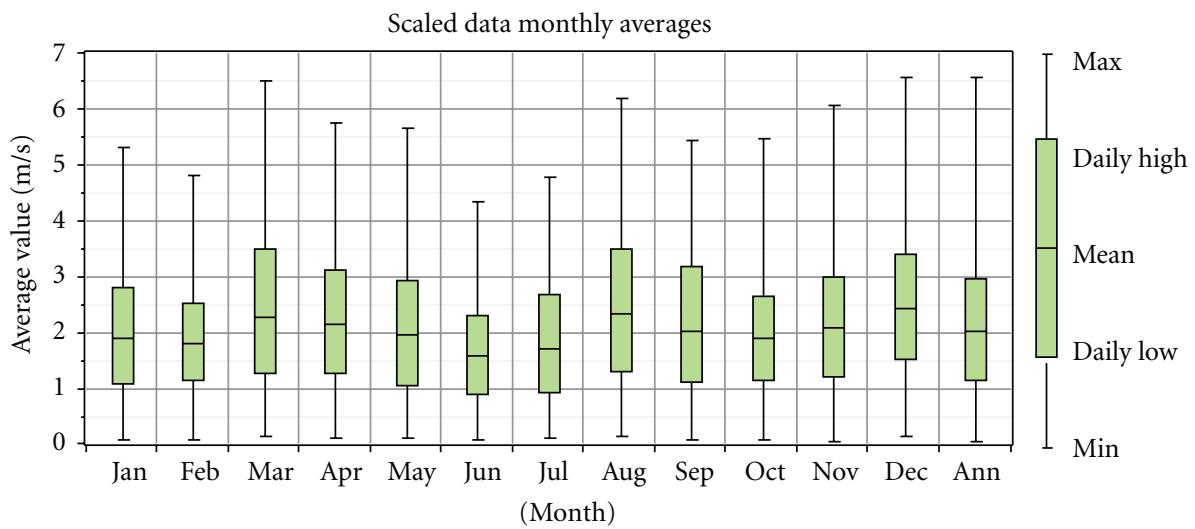

(a)

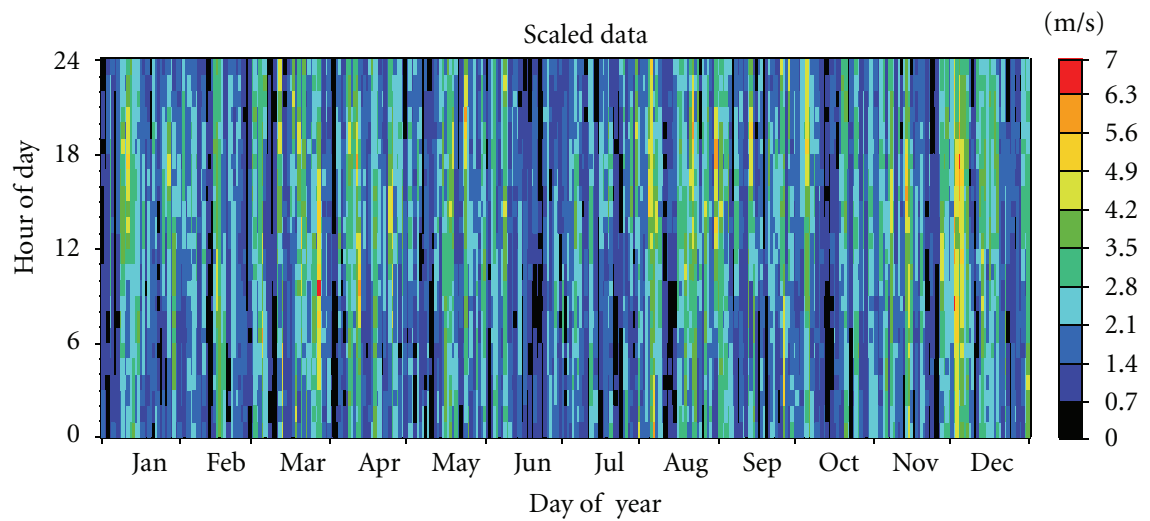

(b)

FIgURE 4: Synthetic series of wind speed at the site of the house at a height of 7 meters.

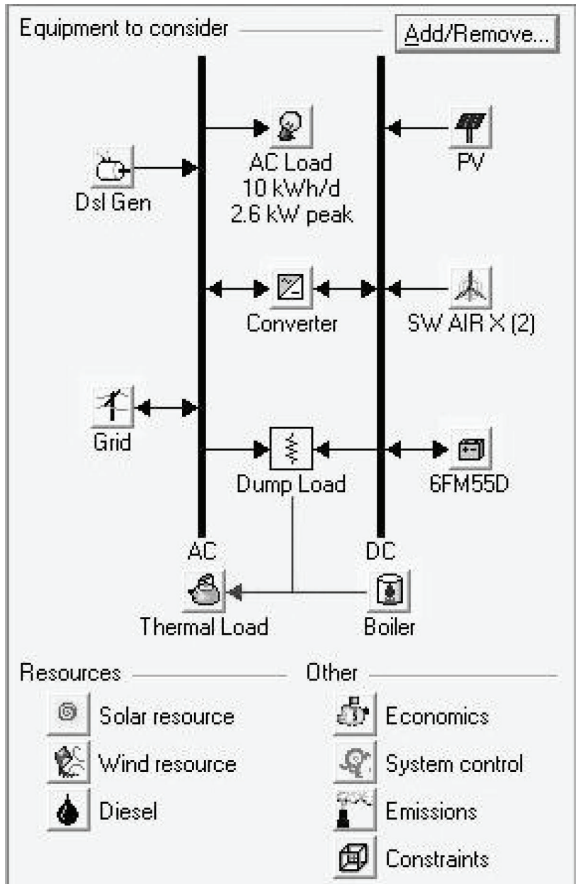

Figure 5: PV wind diesel hybrid system used to supply the house considered in the study.
Simulations were performed for the following values for the optimization variables: $0.00 \mathrm{~kW}, 0.10 \mathrm{~kW}$, and $0.20 \mathrm{~kW}$ for PV modules; 0,1 , and 2 wind turbines; $0 \mathrm{~kW}$ and $2 \mathrm{~kW}$ for diesel generation set; $0,2,4$, and 8 batteries; $0.0 \mathrm{~kW}$ and $1.0 \mathrm{~kW}$ for the converter; $2 \mathrm{~kW}$ for the purchase capacity from the grid, when considered.

Simulations were performed for the following values for the sensitivity inputs: $10 \mathrm{kWh} / \mathrm{d}, 12 \mathrm{kWh} / \mathrm{d}, 14 \mathrm{kWh} / \mathrm{d}$, and $16 \mathrm{kWh} / \mathrm{d}$ for AC load; $2 \mathrm{~m} / \mathrm{s}, 3 \mathrm{~m} / \mathrm{s}, 4 \mathrm{~m} / \mathrm{s}, 5 \mathrm{~m} / \mathrm{s}, 6 \mathrm{~m} / \mathrm{s}, 7 \mathrm{~m} / \mathrm{s}$ and $8 \mathrm{~m} / \mathrm{s}$ for the scaled annual average velocity of the wind; US\$ 0.50 , US\$ 0.80 , US\$ 1.10 , US\$ 1.40 , US $\$ 1.70$, and US\$ 2.00 per liter of diesel; $0.0 \%, 2.5 \%, 5.0 \%, 10.0 \%$, and $15.0 \%$ for maximum annual shortage; and 1.00, 0.75, 0.50, 0.25, $0.10,0.05$ and 0.01 for PV capital cost, PV replacement cost and PV operating and maintenance costs multipliers, these latter two linked to the first.

A set of 288 simulations, with 5880 different values for the variables of sensitivity, were performed. The operation was completed after a total time of about 600 minutes. The results are presented and discussed in the next section.

\section{Results and Discussion}

Results for the simulation of the complete system of Figure 5, connected to the grid, with and without thermal load, 


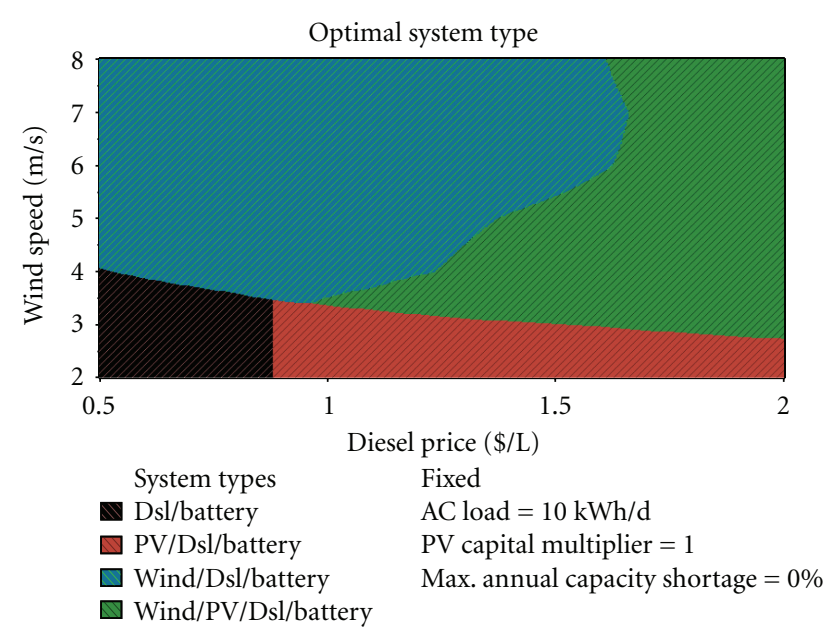

FIGURE 6: Results for the optimization space of the complete system of Figure 5, disconnected from the grid.

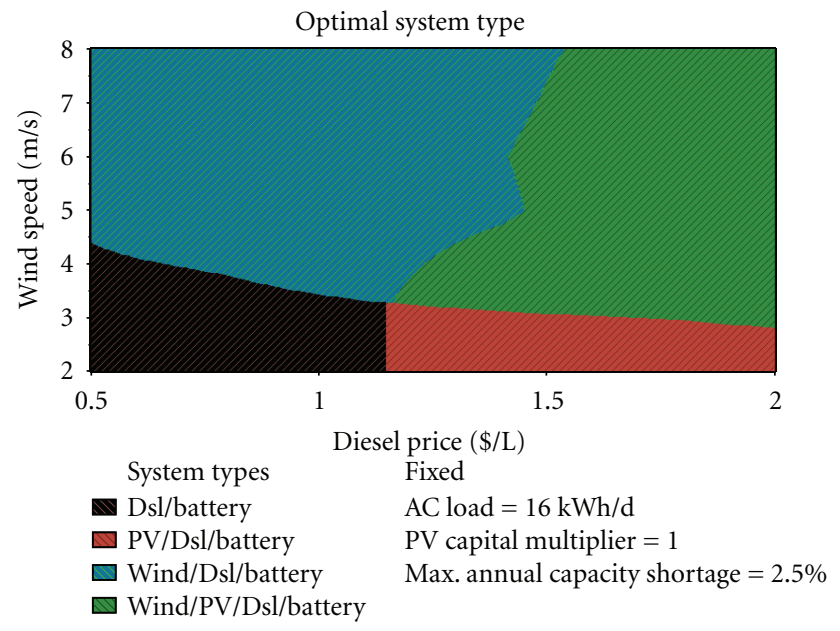

Figure 7: Results for the optimization space of the system of Figure 5 disconnected from the grid, with $16 \mathrm{kWh} / \mathrm{d}$ AC load.

indicate an optimization space with a single solution, which is the combination of connection to the grid with the diesel gen set. The sensitivity results for the system with thermal load displays costs from US\$26,500 to US\$ 67,000 , and the system without thermal load displays costs from US\$ 13,000 to US\$14,250. The cost of energy was between US\$ $0.280 / \mathrm{kWh}$ and US $\$ 0.305 / \mathrm{kWh}$ in both cases, as expected.

Results for the simulation of the system of Figure 5 disconnected from the grid are shown in Figure 6. A line of solutions including wind turbines is clearly visible. Above that line solutions include wind, not below. Below left, the solutions include diesel gen set and batteries; right, including also PV. Above, the solutions that include or not include PV have costs that are very close.

Results for the system of Figure 5 disconnected from the grid and with $16 \mathrm{kWh} / \mathrm{d}$ AC load are shown in Figure 7. This figure, the solution space is quite similar to the previous

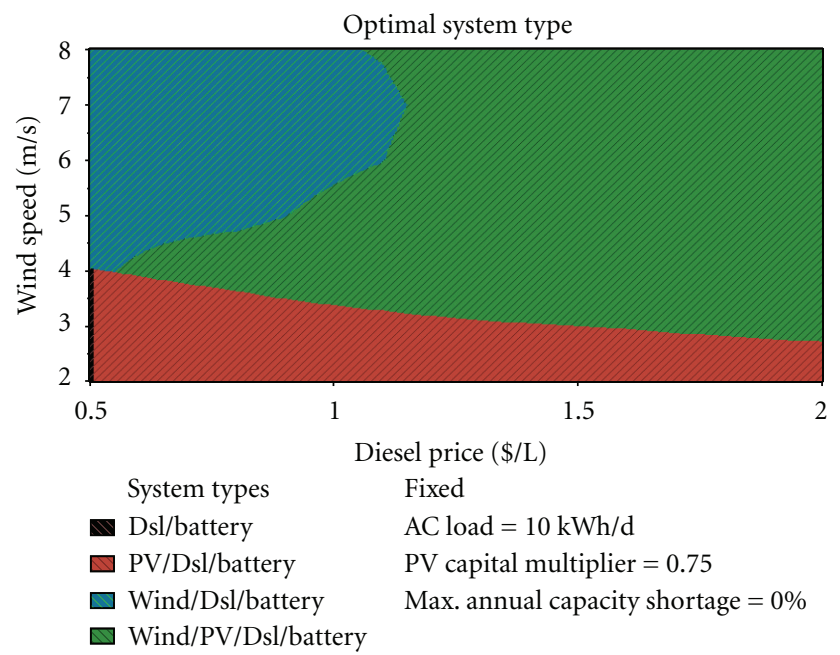

FIGURE 8: Results for the optimization space of the system of Figure 5 disconnected from the grid, with PV capital multiplier equal to 0.75 .

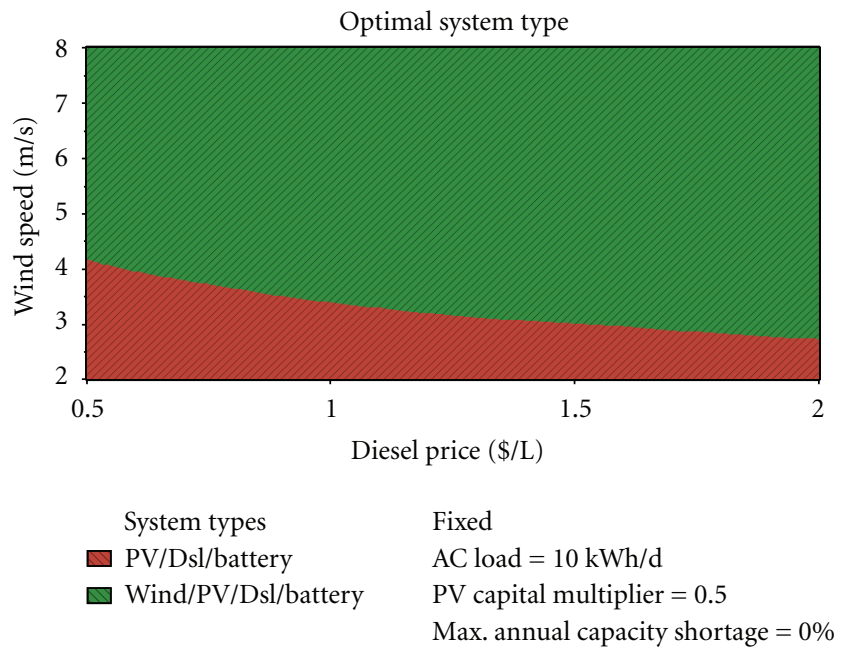

FIGURE 9: Results for the simulation of the complete system of Figure 5 disconnected from the grid, with PV capital multiplier equal to 0.50 .

figure, with as light elevation of the line that separates the solutions which include those that do not include wind.

Results for the simulation of the system of Figure 5 disconnected from the grid, with PV capital cost multiplier of 0.50 and 0.75 are, respectively, shown in Figures 8 and 9. In these two figures, it can be seen increasing the area occupied in the solution space by those who include PV modules.

A 50\% reduction in the cost of modules allows the entire space of solutions including PV modules. Lesser reductions would allow a substantial proportion of the space of solutions including PV modules.

A larger amount of energy is obtained from PV modules with reduced costs, a lower cost of acquisition, and lower operating and maintenance costs. 
Unfortunately, it was not possible to establish a relationship between the penetration of the modules and the reduction in costs because of the limitation imposed by the family in the size of the system components.

In a system with limiting the size of its components, as in this study, consideration of the possible complementarity between energy resources can improve system performance. Reference [7] presents important notions on this subject.

\section{Conclusions}

The simulations showed the solution to the system considered in this study. Furthermore, the simulations considering reduced prices for the modules showed that with 50\% cheaper modules, it would be possible to have modules at each point of the solution space.

This result should serve as a horizon for policy makers to encourage the use of renewable resources, specifically PV modules.

\section{Acknowledgments}

This work was developed as a part of research activities on renewable energy developed at the Instituto de Pesquisas Hidráulicas, Universidade Federal do Rio Grande do Sul. The authors acknowledge the support received by the institution and the receptivity found among the owners of the residence considered in this study, which do not want their identity disclosed.

\section{References}

[1] M. T. Iqbal, "A feasibility study of a zero energy home in Newfoundland," Renewable Energy, vol. 29, no. 2, pp. 277-289, 2004.

[2] Software HOMER, "version 2.68 beta," The Micropower Optimization Model, Homer Energy, http://www.homerenergy. com.

[3] Southwest Windpower. Turbine model SW Air Breeze, http:// www.windenergy.com/products/air/air-breeze.

[4] Vision Group, "Battery model 6FM55D," http://www.visionbatt.com.

[5] T. W. Lambert, P. Gilman, and P. D. Lilienthal, "Micropower system modeling with Homer," in Integration of Alternative Sources of Energy, F. A. Farret and M. G. Simões, Eds., pp. 379418, John Wiley \& Sons, 2005.

[6] P. D. Lilienthal, T. W. Lambert, and P. Gilman, "Computer modeling of renewable power systems," in Encyclopedia of Energy, C. J. Cleveland, Ed., vol. 1, pp. 633-647, Elsevier, 2004, NREL Report CH-710-36771.

[7] A. Beluco, P. K. :Souza, and A. Krenzinger, "A dimensionless index evaluating the time complementarity between solar and hydraulic energies," Renewable Energy, vol. 33, no. 10, pp. 21572165, 2008. 


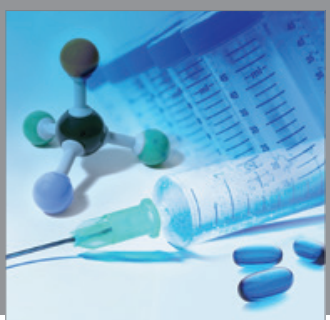

International Journal of

Medicinal Chemistry

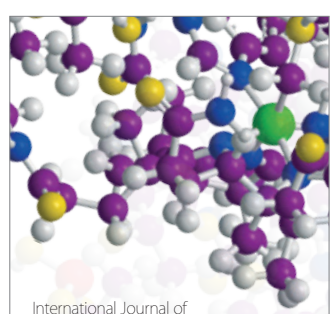

Carbohydrate Chemistry

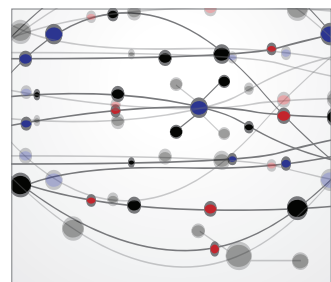

The Scientific World Journal
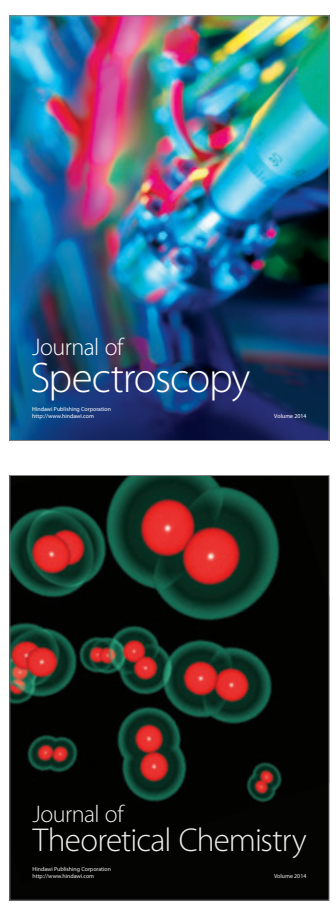
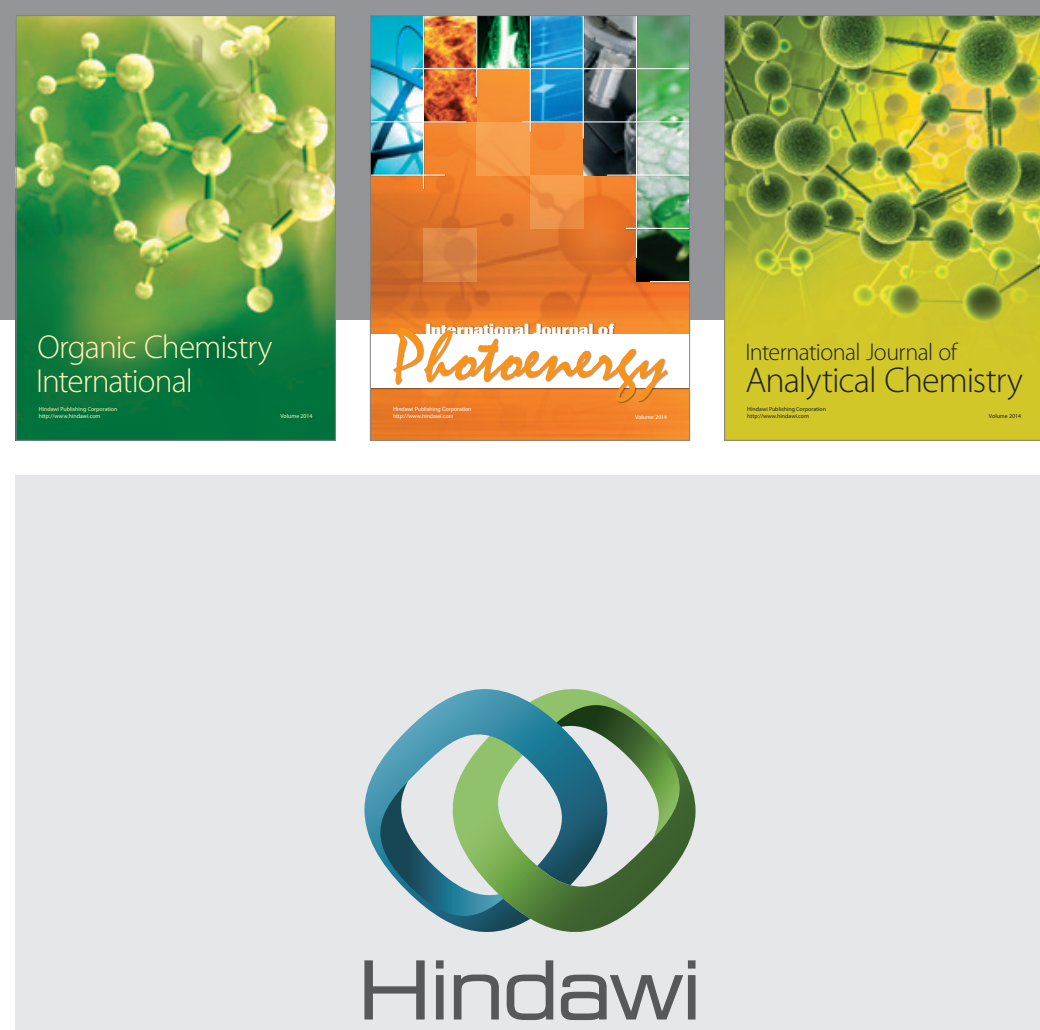

Submit your manuscripts at

http://www.hindawi.com
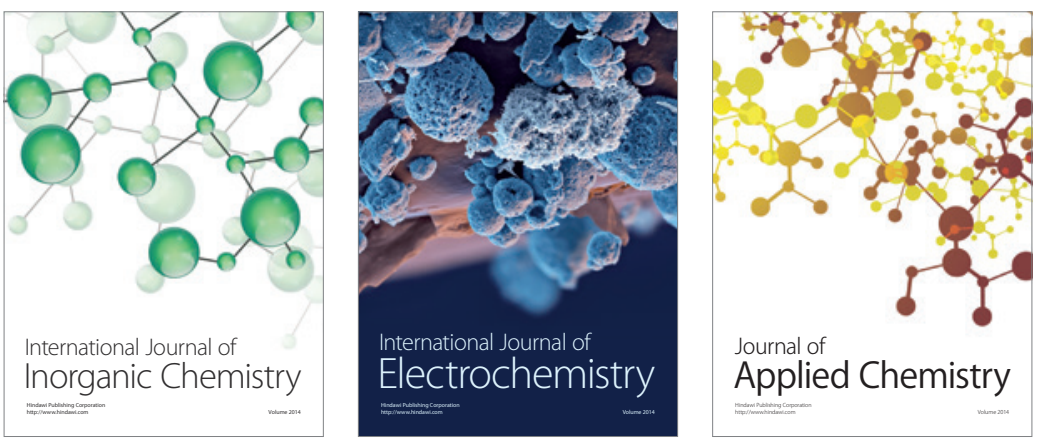

Journal of

Applied Chemistry
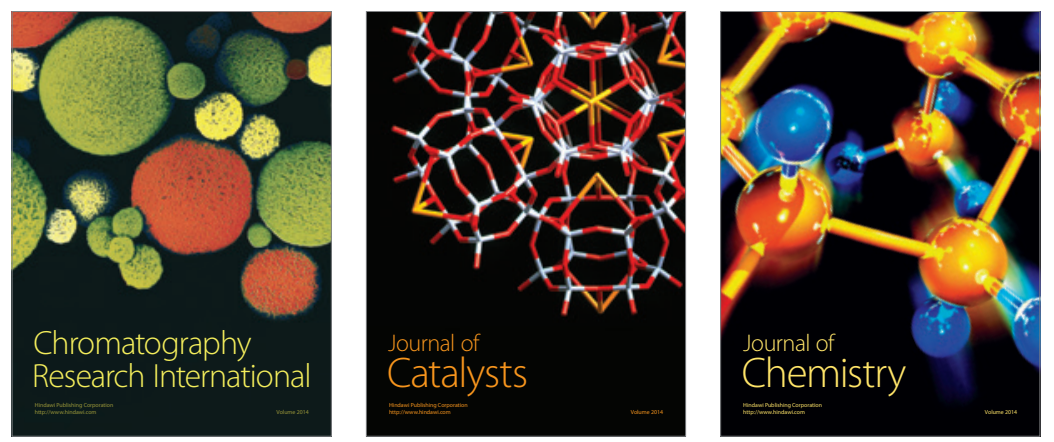
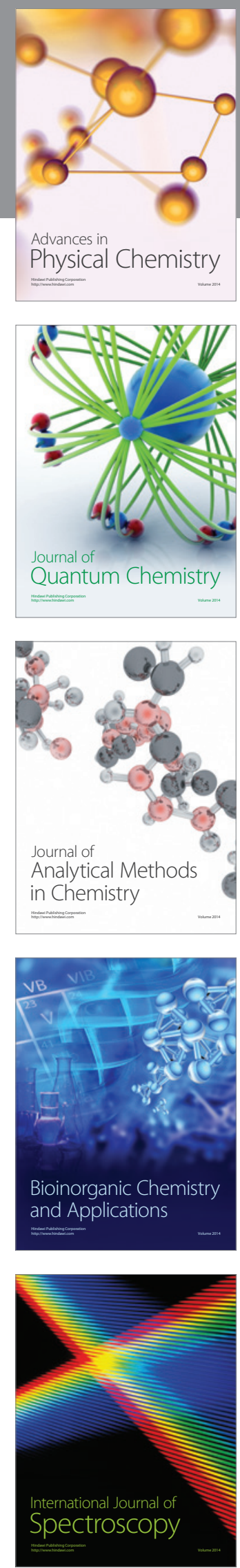